classification criteria for AS. Less patients with late onset disease were HLAB27 positive, the reason for this is unknow. These patients had worse functional outcomes, which could reflect the older age of symptom onset. It is notable that patients with late onset AS are being treated with less biologic agents, and have a slightly higher rate of NSAID usage. Additional registry studies into this subgroup would help to understand these variations in medication usage and prescribing practices.

Disclosure of Interests: Sinead Maguire Grant/research support from: ASRI is supported by funding from Pfizer, AbbVie and UCB, Phil Gallagher: None declared, Finbar Barry O'Shea Grant/research support from: ASRI is supported by funding from Pfizer, AbbVie and UCB

DOI: 10.1136/annrheumdis-2020-eular.1307

\section{SAT0383 ENHANCED PERFORMANCE OF THE ASAS CLASSIFICATION CRITERIA BY DELETION OF NON- DISCRIMINATORY CLINICAL ITEMS: DATA FROM THE SCREENING IN AXIAL SPONDYLOARTHRITIS IN PSORIASIS, IRITIS, AND COLITIS COHORT}

W. P. Maksymowych ${ }^{1,2}$, R. Carmona ${ }^{3}$, J. Chan $^{4}$, J. Yeung ${ }^{5}$, S. Aydin ${ }^{6}$,

L. Martin ${ }^{7}$, A. Masetto ${ }^{8}$, O. Ziouzina ${ }^{7}$, S. Keeling ${ }^{1}$, S. Rohekar ${ }^{9}$, R. Dadashova ${ }^{2}$, J. Paschke ${ }^{2}$, A. Carapellucci ${ }^{2}$, R. G. Lambert ${ }^{1}{ }^{1}$ University of Alberta,

Edmonton, Canada; ${ }^{2}$ CARE Arthritis, Edmonton, Canada; ${ }^{3}$ St. Joseph's Healthcare Hamilton, Hamilton, Canada; ${ }^{4}$ Artus Health Centre, Vancouver, Canada; ${ }^{5}$ James Yeung Rheumatology, Richmond, Canada; ${ }^{6}$ The Ottawa Hospital, Ottawa, Canada; ${ }^{7}$ University of Calgary, Calgary, Canada; ${ }^{8}$ Université de Sherbrooke, Sherbrooke, Canada; ${ }^{9}$ Lawson Health Research Institute, London, Canada

Background: The ASAS classification criteria for axial spondyloarthritis (axSpA) have overall sensitivity/specificity of $82.9 \% / 84.4 \%$ but component imaging and clinical arms differ in performance $(66.2 \% / 97.3 \%$ and $56.6 \% / 83.3 \%$, respectively) ${ }^{1}$.

Objectives: We aimed to demonstrate that a data-driven elimination of SpA clinical features that were non-discriminatory in comparisons of patients diagnosed with and without axSpA in a prospective cohort of patients with undiagnosed back pain could enhance the performance of the criteria.

Methods: We used data from the prospective multicenter Screening for Axial Spondyloarthritis in Psoriasis, Iritis, and Colitis (SASPIC) Study. Consecutive patients $\leq 45$ years of age with $\geq 3$ months undiagnosed back pain with any one of psoriasis, AAU, or colitis undergo routine diagnostic evaluation by a rheumatologist for axial $\mathrm{SpA}$, including imaging assessed by central readers. Univariable and multivariable logistic regression analysis was performed to determine which clinical SpA features were/were not discriminatory for the final diagnosis of axSpA. We then compared the sensitivity and specificity of the ASAS criteria with and without these features.

Results: A total of 246 patients were recruited, $47.6 \%$ being diagnosed with axSpA (61.5\% male, age 33.7 years, symptom duration 7.6 years, B27 positive $52.1 \%)$. The following clinical SpA features were non-discriminatory between axSpA/not axSpA: NSAID response, family history of SpA, heel enthesitis, peripheral arthritis, dactylitis. Specificity of the clinical arm and the overall criteria increased from $82.2 \%$ to $86.8 \%$ without impacting sensitivity. This effect was particularly noteworthy in patients with lower degree of symptomatology (back pain severity $<5 / 10$, specificity increases from $76.7 \%$ to $90.7 \%$ ), short symptom

\begin{tabular}{|c|c|c|c|c|c|c|c|}
\hline \multirow[t]{2}{*}{ Patient Category } & \multirow[t]{2}{*}{ Number } & \multicolumn{2}{|c|}{$\begin{array}{l}\text { ASAS } \\
\text { criteria }\end{array}$} & \multicolumn{2}{|c|}{$\begin{array}{c}\text { Imaging } \\
\text { arm }\end{array}$} & \multicolumn{2}{|c|}{ Clinical arm } \\
\hline & & Sen & Spec & Sen & Spec & Sens & Spec \\
\hline All patients & 246 & 65 & 82.2 & 36.8 & 97.7 & 50.4 & 82.2 \\
\hline High confidenc & 190 & 73.8 & 84.5 & 47.5 & 98.2 & 56.3 & 84.5 \\
\hline Patients with back pain $\geq 5 / 10$ & 165 & 63.3 & 84.9 & 34.2 & 98.8 & 51.9 & 84.9 \\
\hline Patients with back pain $<5$ & 81 & 68.4 & 76.7 & 42.1 & 95.3 & 47.4 & 76.7 \\
\hline Patients with symptom duration $\geq 5$ years & 103 & 71.2 & 85.7 & 35.6 & 97.1 & 56.2 & 85.7 \\
\hline Patients with symptom duration $<5$ years & 143 & 54.5 & 78 & 38.6 & 98.3 & 40.9 & 78 \\
\hline Males & 129 & 68.1 & 84.2 & 47.2 & 98.2 & 48.6 & 84.2 \\
\hline Females & 117 & 60 & 80.6 & 20 & 97.2 & 53.3 & 80.6 \\
\hline \multicolumn{8}{|c|}{$\begin{array}{l}\text { After deletion of 'NSAID response', 'Family Hx SpA', 'heel enthesitis', 'peripheral arthri- } \\
\text { tis', 'dactylitis' SpA features }\end{array}$} \\
\hline All patients & 246 & 65 & 86.8 & 36.8 & 97.7 & 50.4 & 86.8 \\
\hline High confidence in diagnosis & 190 & 73.8 & 87.3 & 47.5 & 98.2 & 56.3 & 87.3 \\
\hline Patients with back pain $\geq 5 / 10$ & 165 & 63.3 & 84.9 & 34.2 & 98.8 & 51.9 & 84.9 \\
\hline Patients with back pain $<5$ & 81 & 68.4 & 90.7 & 42.1 & 95.3 & 47.4 & 90.7 \\
\hline Patients with symptom duration $\geq 5$ years & 103 & 71.2 & 88.6 & 35.6 & 97.1 & 56.2 & 88.6 \\
\hline Patients with symptom duration $<5$ years & 143 & 54.5 & 84.7 & 38.6 & 98.3 & 40.9 & 84.7 \\
\hline Males & 129 & 68.1 & 87.7 & 47.2 & 98.2 & 48.6 & 87.7 \\
\hline Females & 117 & 60 & 86.1 & 20 & 97.2 & 53.3 & 86.1 \\
\hline
\end{tabular}

duration ( $<5$ years, specificity increases from $78 \%$ to $84.7 \%$ ), and in females (specificity increases from $80.6 \%$ to $86.1 \%$ ).

Conclusion: In a prospective cohort with a high pre-test probability of axSpA certain clinical SpA features were not helpful in discriminating a diagnosis of SpA from not-SpA. Deletion of these features from the list of $\mathrm{SpA}$ features used in the ASAS classification criteria enhanced the performance of the criteria, especially in female patients and those with early disease.

References:

[1] Rudwaleit et al. Ann Rheum Dis 2009;68: 777-83

Disclosure of Interests: Walter P. Maksymowych Grant/research support from: AbbVie, Novartis, Pfizer, and UCB, Consultant of: AbbVie, Boehringer Ingelheim, Celgene, Eli Lilly, Galapagos, Janssen, Novartis, Pfizer, and UCB, Employee of: Chief Medical Officer of CARE Arthritis Limited, Speakers bureau: AbbVie, Janssen, Novartis, Pfizer, and UCB, Raj Carmona: None declared, Jon Chan: None declared, James Yeung: None declared, Sibel Aydin: None declared, Liam Martin: None declared, Ariel Masetto: None declared, Olga Ziouzina: None declared, Stephanie Keeling: None declared, Sherry Rohekar: None declared, Rana Dadashova: None declared, Joel Paschke: None declared, Amanda Carapellucci: None declared, Robert G Lambert: None declared

DOI: 10.1136/annrheumdis-2020-eular.5947

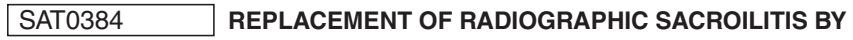 MRI STRUCTURAL LESIONS: WHAT IS THE IMPACT ON CLASSIFICATION OF AXIAL SPONDYLOARTHRITIS IN THE ASAS CLASSIFICATION COHORT?}

W. P. Maksymowych ${ }^{1,2}$, P. M. Machado ${ }^{3}$, R. G. Lambert ${ }^{1}$, X. Baraliakos ${ }^{4}$, M. Ǿstergaard ${ }^{5}$, J. Sieper ${ }^{6}$, S. Wichuk ${ }^{1}$, D. Poddubnyy ${ }^{6}$, M. Rudwaleit ${ }^{7}$, D. Van der Heijde ${ }^{8}$, R. B. M. Landewé9 ${ }^{\text {, J. } \text { Paschke }^{2} \text {, S. Juhl Pedersen }}{ }^{5}$, U. Weber ${ }^{10}$. ${ }^{1}$ University of Alberta, Edmonton, Canada; ${ }^{2}$ CARE Arthritis, Edmonton, Canada; ${ }^{3}$ University College London, London, United Kingdom; ${ }^{4}$ Rheumazentrum Ruhrgebiet, Herne, Germany; ${ }^{5}$ Copenhagen University, Copenhagen, Denmark; ${ }^{6}$ Charité - Universitätsmedizin Berlin, Berlin, Germany; ${ }^{7}$ Klinikum Bielefeld, Bielefeld, Germany; ${ }^{8}$ Leiden University Medical Center, Leiden, Netherlands; ${ }^{9}$ University of Amsterdam,

Amsterdam, Netherlands; ${ }^{10}$ University of Southern Denmark, Sønderborg, Denmark

Background: Classification of axial spondyloarthritis (axSpA) is based on either an imaging or clinical arm. Radiographic or MRI evidence of sacroiliitis can be applied for the imaging arm. However, it is well-established that reliability and sensitivity of radiographic sacroiliitis is inadequate.

Objectives: To assess the impact of replacing radiographic sacroiliitis with MRI structural lesions (MRI-S) typical of axSpA on the number of patients classified as having axSpA in patients with undiagnosed back pain recruited to the ASAS Classification Cohort (ASAS-CC).

Methods: MRI images of the sacroiliac joint (SIJ) were available from 217 cases in the ASAS-CC, which also had clinical, laboratory, and radiographic data. Seven central readers from the ASAS-MRI group recorded MRI lesions in an eCRF that included active (MRI-A) and structural (MRI-S) lesions typical of axSpA. MRI-A was deemed to be present according to majority agreement $(\geq 4 / 7)$ of central readers. MRI-S was deemed to be present according to the majority (majority reader MRI-S) and also according to at least 2 central readers ( $\geq 2$-reader MRI$\mathrm{S})$. We calculated the number of patients that were classified differently after replacement of radiographs by MRI-S for overall fulfillment of the ASAS criteria and for the imaging arm.

Results: In total, 119 (54.8\%) cases fulfilled the axSpA criteria based on loca reading of radiographic sacroiliitis and central reading of active inflammation on MRI. This changed to 125 (57.6\%) and 118 (54.4\%) of cases after replacement of radiographic sacroiliitis by $\geq 2$-reader and majority reader MRI-S, respectively (Table). A total of $13(6.0 \%)$ and 7 (3.2\%) cases who were classified as not having axSpA were re-classified as having axSpA after replacing radiographic sacroiliitis with $\geq 2$-reader and majority reader MRI-S, respectively. Conversely, 7 (3.2\%) and $8(3.7 \%)$ cases were re-classified as not having axSpA after substitution by $\geq 2$-reader and majority reader MRI-S, respectively. When fulfillment of the imaging arm was the primary consideration (irrespective of the clinical arm), the number of patients reclassified from not axSpA to axSpA was $25(11.5 \%)$ by $\geq 2$-reader and $13(6.0 \%)$ by majority reader MRI-S, while $8(3.7 \%)$ and $11(5.1 \%)$ were reclassified from axSpA to not axSpA.

Conclusion: The number of patients classified as having axSpA does not change substantially when MRI-S replaces radiographic sacroiliitis. However, it remains possible that MRI structural lesions can influence the final diagnosis, the gold standard for assessment of the performance of the ASAS criteria. 
Impact of Replacement of Radiographic Sacroilitis by MRI Structural Lesions on SpA Classification in cases with all clinical, radiographic, and central and local MRI inflammation data available $(n=217)$

\begin{tabular}{|c|c|c|c|c|}
\hline MRI assessment used & $\begin{array}{l}\text { SpA Classification=Yes } \\
\qquad N(\%)\end{array}$ & $\begin{array}{c}\text { SpA Classification=No } \\
\qquad \mathrm{N}(\%)\end{array}$ & $\begin{array}{c}\text { Imaging Arm SpA } \\
\text { Classification=Yes N(\%) }\end{array}$ & $\begin{array}{c}\text { Imaging Arm SpA } \\
\text { Classification=No N(\%) }\end{array}$ \\
\hline $\begin{array}{l}\text { Radiographic Sacroiliitis + Majority Central } \\
\text { Reader MRI Inflammation Positive }\end{array}$ & $119(54.8 \%)$ & $97(44.7 \%)$ & $83(38.2 \%)$ & $134(61.8 \%)$ \\
\hline Replace Radiographic Sacroiliitis with $\geq 2$ & $125(57.6 \%)$ & $92(42.4 \%)$ & $100(46.1 \%)$ & 117 (53.9\%) \\
\hline $\begin{array}{l}\text { Central Reader MRI Structural Positive } \\
\text { Replace Radiographic Sacroiliitis with } \\
\text { Majority Central Reader MRI Structural } \\
\text { Positive }\end{array}$ & $118(54.4 \%)$ & $99(45.6 \%)$ & $85(39.2 \%)$ & $132(60.8 \%)$ \\
\hline
\end{tabular}

Disclosure of Interests: Walter P. Maksymowych Grant/research support from: AbbVie, Novartis, Pfizer, and UCB, Consultant of: AbbVie, Boehringer Ingelheim, Celgene, Eli Lilly, Galapagos, Janssen, Novartis, Pfizer, and UCB, Employee of: Chief Medical Officer of CARE Arthritis Limited, Speakers bureau: AbbVie, Janssen, Novartis, Pfizer, and UCB, Pedro M Machado Consultant of: PMM: Abbvie, Celgene, Janssen, Lilly, MSD, Novartis, Pfizer, Roche and UCB, Speakers bureau: PMM: Abbvie, BMS, Lilly, MSD, Novartis, Pfizer, Roche and UCB, Robert G Lambert: None declared, Xenofon Baraliakos Grant/research support from: Grant/ research support from: AbbVie, BMS, Celgene, Chugai, Merck, Novartis, Pfizer, UCB and Werfen, Consultant of: AbbVie, BMS, Celgene, Chugai, Merck, Novartis, Pfizer, UCB and Werfen, Speakers bureau: AbbVie, BMS, Celgene, Chugai, Merck, Novartis, Pfizer, UCB and Werfen, Mikkel Ǿstergaard Grant/research support from: AbbVie, Bristol-Myers Squibb, Celgene, Merck, and Novartis, Consultant of: AbbVie, Bristol-Myers Squibb, Boehringer Ingelheim, Celgene, Eli Lilly, Hospira, Janssen, Merck, Novartis, Novo Nordisk, Orion, Pfizer, Regeneron, Roche, Sandoz, Sanofi, and UCB, Speakers bureau: AbbVie, Bristol-Myers Squibb, Boehringer Ingelheim, Celgene, Eli Lilly, Hospira, Janssen, Merck, Novartis, Novo Nordisk, Orion, Pfizer, Regeneron, Roche, Sandoz, Sanofi, and UCB, Joachim Sieper Consultant of: AbbVie, Boehringer Ingelheim, Eli Lilly and Company, Janssen, Merck, Novartis, Pfizer, Roche, and UCB Pharma, Speakers bureau: AbbVie, Boehringer Ingelheim, Eli Lilly and Company, Janssen, Merck, Novartis, Pfizer, Roche, and UCB Pharma, Stephanie Wichuk: None declared, Denis Poddubnyy Grant/research support from: AbbVie, MSD, Novartis, and Pfizer, Consultant of: AbbVie, Bristol-Myers Squibb, Eli Lilly, MSD, Novartis, Pfizer, Roche, UCB, Speakers bureau: AbbVie, Bristol-Myers Squibb, Eli Lilly, MSD, Novartis, Pfizer, Roche, UCB, Martin Rudwaleit Consultant of: AbbVie, BMS, Celgene, Janssen, Eli Lilly, MSD, Novartis, Pfizer, Roche, UCB Pharma, Désirée van der Heijde Consultant of: AbbVie, Amgen, Astellas, AstraZeneca, BMS, Boehringer Ingelheim, Celgene, Cyxone, Daiichi, Eisai, Eli-Lilly, Galapagos, Gilead Sciences, Inc., Glaxo-SmithKline, Janssen, Merck, Novartis, Pfizer, Regeneron, Roche, Sanofi, Takeda, UCB Pharma; Director of Imaging Rheumatology BV, Robert B.M. Landewé Consultant of: AbbVie; AstraZeneca; Bristol-Myers Squibb; Eli Lilly \& Co.; Galapagos NV; Novartis; Pfizer; UCB Pharma, Joel Paschke: None declared, Susanne Juhl Pedersen Grant/research support from: Novartis, Ulrich Weber: None declared DOI: 10.1136/annrheumdis-2020-eular.6369

\section{SAT0385 CAN MISCLASSIFICATION BETWEEN SPONDYLOARTHRITIS (SPA) AND RHEUMATOID ARTHRITIS (RA) OCCUR? SPA-RELATED CLINICAL MANIFESTATIONS AMONG RA AND SPA PATIENTS - A SYSTEMATIC LITERATURE REVIEW}

P. J. Mease ${ }^{1}$, M. K. Bhutani ${ }^{2}$, P. Hur ${ }^{3}$, E. Yi ${ }^{3}$, N. Kim ${ }^{4} .{ }^{1}$ Swedish Medical Centre/ Providence St Joseph Health, and University of Washington, Seattle, WA, United States of America; ${ }^{2}$ Novartis Healthcare Pvt Ltd, Hyderabad, India; ${ }^{3}$ Novartis Pharmaceuticals Corporation, East Hanover, NJ, United States of America; ${ }^{4}$ Baylor Scott \& White Health, Temple, TX and University of Texas at Austin, Austin, TX, United States of America

Background: Delayed diagnosis is associated with worse outcomes and poor treatment responses in patients with $\mathrm{SpA}$, including psoriatic arthritis $(\mathrm{PsA})$ and axial spondyloarthritis. ${ }^{1}$ Misclassification may be associated with this delay, as SpA and RA, especially seronegative RA, may present with similar manifestations such as joint pain, swelling, fatigue, and disability. Key features that typically distinguish SpA from RA include spine pain, dactylitis, enthesitis, psoriasis, and nail psoriasis. ${ }^{2}$ Increased physician awareness of the potential overlap and distinctions between SpA and RA manifestations is needed for the early diagnosis and appropriate treatment for SpA.

Objectives: To identify and summarise the published literature on the prevalence of SpA-related clinical manifestations among patients with RA and SpA. Methods: Publications were retrieved from Embase $®$, Cochrane, MEDLINE $₫$, and MEDLINE $®$ In-Process databases. Studies were included if they were non-interventional, recruited patients with RA and $\mathrm{SpA}$, or patients with seronegative/seropositive RA, and reported the following manifestations: enthesitis, dactylitis, axial symptoms, psoriasis, or nail psoriasis. Two reviewers assessed each citation against predefined eligibility criteria, with discrepancies reconciled by a third independent reviewer.

Results: Of the 4479 publications retrieved, 18 studies were included (Figure 1). All studies compared SpA populations to patients with RA. Of the 18 studies, 11 studies reported patients with only PsA, 2 studies reported patients with only ankylosing spondylitis (AS), and 5 studies reported mixed SpA populations. Three studies each reported data pertaining to seropositive/seronegative RA and early RA, defined as symptom onset $<1$ year. The majority ( $N=12)$ of studies used ultrasound imaging to identify manifestations of interest. Enthesitis $(\mathrm{N}=17)$ was the most frequently evaluated manifestation while axial symptoms $(\mathrm{N}=2)$ was least evaluated. Of the studies reporting enthesitis, the majority $(\mathrm{N}=14)$ reported a higher prevalence of enthesitis in the SpA cohort compared to the RA cohort. The remaining studies $(\mathrm{N}=3)$ reported no significant difference in enthesitis between the SpA and RA cohorts. Notably, these 3 studies comprised of the 2 studies evaluating only AS patients, and all 3 studies evaluated late RA patients. In contrast, the 3 studies that reported early RA and PSA patients found a significantly higher prevalence of enthesitis in early PsA vs. early RA cohort. Two of the 3 studies reporting RA serostatus found a higher prevalence of enthesitis, psoriasis, and/or nail psoriasis in the $\mathrm{SpA}$ population compared to seronegative and seropositive RA cohorts. All studies reporting axial symptoms, dactylitis, psoriasis, and nail psoriasis found a higher prevalence of the corresponding manifestation in the SpA vs. RA cohort.

Conclusion: While this review found a higher prevalence of key SpA-related clinical manifestations in SpA vs. RA, overlap was present suggesting that misclassification could occur. Differences in the prevalence of manifestations were also seen in the early vs. late RA populations as well as by RA serostatus. This suggests that an earlier and comprehensive evaluation, including advanced imaging of peripheral manifestations such as enthesitis, dactylitis, axial symptoms, and skin signs such as psoriasis and nail disease, among RA and SpA patients may reduce misclassification and inappropriate treatment. Further research is needed to confirm these findings.

\section{References:}

[1] Seo et al. Clin Rheumatol. 2015;34:1397-1405.

[2] Merola et al. RMD. 2018;4:e000656.

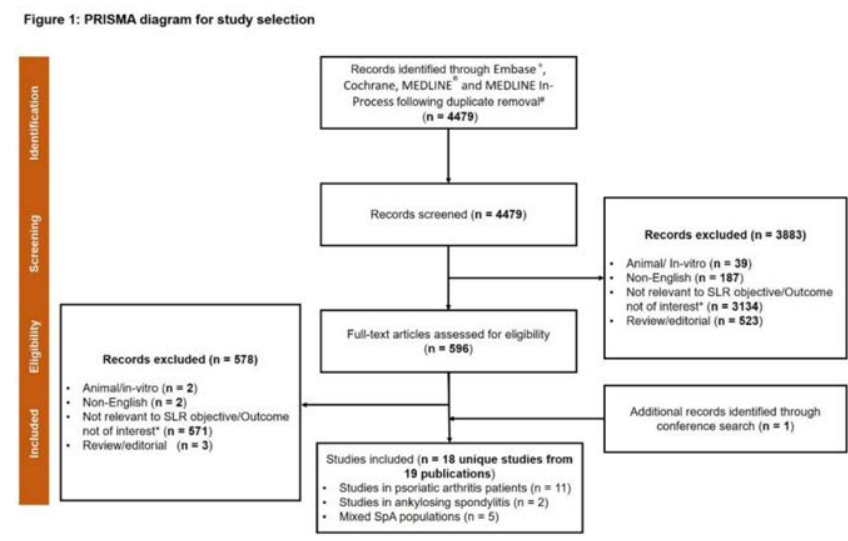

"Studies reporting data pertaining to enthesitis, dactyitis, psoriasis, inflammatory back pain, and nail psoriasis for spondyloarthritis "Databases were searched till 10 October 2019; the procoedings from ACR and EULAR conferences were also searched for the
last two years 